\title{
PESQUISA EDUCACIONAL SOBRE MST E EDUCAÇÃO DO CAMPO NO BRASIL
}

\author{
MARIA ANTÔNIA DE SOUZA ${ }^{1 ; 2 ; 3}$ \\ ORCID: https://orcid.org/0000-0001-7514-8382
}

\begin{abstract}
RESUMO: Este trabalho caracteriza o estágio atual da pesquisa educacional sobre o Movimento dos Trabalhadores Rurais Sem Terra (MST) e Educação do Campo. É fruto de investigação bibliográfica de teses e dissertações sobre o (MST), desde 1986, e a Educação do Campo a partir de 2002. Os procedimentos de pesquisa foram: consulta ao banco de teses da Capes; levantamento de dados nos currículos dos pesquisadores; análise das listas de referências dos livros, teses e dissertações vinculados ao tema e análise de conteúdo das pesquisas. Foram identificadas 1.310 pesquisas produzidas nos programas de pós-graduação stricto sensu da área da educação no Brasil, e selecionadas 359 sobre o MST e 763 sobre a Educação do Campo. A produção concentra-se na Região Centro-Sul do País, embora haja expressivo número de pesquisas nas regiões Norte e Nordeste. Os eixos temáticos centrais das teses e dissertações são: formação de professores, prática educativa, políticas públicas e organização do trabalho pedagógico.
\end{abstract}

Palavras-chave: Pesquisa Educacional. MST. Educação do Campo.

\section{THE EDUCATIONAL RESEARCH ON SOCIAL MOVEMENTS AND COUNTRYSIDE EDUCATION IN BRAZIL}

\begin{abstract}
The present study caracterizes the current stage of educational research on Landless Movement and countryside education. It is the result of bibliographic research on theses and dissertations that have aimed at investigating the Movement of Landless Rural Workers (MST), since 1986 and the countryside education from 2002, especially. The research procedures were: consulting the theses bank of Capes; collection of data in the curricula of researchers; analysis of the lists of references of books, theses and dissertations and analysis of the content of the researches. It was possible to identify 1.310 researches produced in stricto sensu graduate programs in education in Brazil and were selected 359 on MST and 763 on countryside education. The production is concentrated in the south central region of the country, although there is a significant number of searches in the north and northeast regions. The main themes of the theses and dissertations are: education policy, teachers' training, educational practice and organization of pedagogical work.
\end{abstract}

Keywords: Educational research. Landless Movement. Countryside education.

\footnotetext{
${ }^{1}$ Universidade Tuiuti do Paraná, Programa de Pós-Graduação em Educação, Curitiba, PR, Brasil.

${ }^{2}$ Universidade Estadual de Ponta Grossa, Curso de Pedagogia, Ponta Grossa, PR, Brasil.

${ }^{3}$ Doutora em Educação pela Universidade Estadual de Campinas, bolsista Produtividade em Pesquisa 1B, Coordenadora do Núcleo de Pesquisa em Educação do Campo, Movimentos Sociais e Práticas Pedagógicas, Universidade Tuiuti do Paraná. Email:maria.antonia@pq.cnpq.br
} 


\section{INTRODUÇÃO}

O objetivo deste artigo é caracterizar a produção do conhecimento educacional sobre o Movimento dos Trabalhadores Rurais Sem Terra (MST) e a Educação do Campo, no período de 1986 a 2018, no Brasil. O recorte temporal é feito com base no fato de que a concepção de Educação do Campo se torna pública no ano de 1998, durante a I Conferência Nacional por uma Educação do Campo, e também no fato de que as pesquisas educacionais sobre o MST tiveram início em 1986. As primeiras pesquisas educacionais na pós-graduação que utilizaram o conceito de Educação do Campo são de 2002.

Há mais de 20 anos realizamos pesquisas sobre a presença do MST na produção do conhecimento educacional e identificamos a tendência de associação do conceito de Educação do Campo aos processos formativos com os povos do campo, tanto em áreas de acampamento e assentamento, quanto em comunidades da agricultura familiar. O conceito de Educação do Campo tem como componente identitário o protagonismo dos trabalhadores do campo e dos coletivos que os representam, bem como a defesa de outro projeto societário. É conceito que emerge da prática social como experiência coletiva, gera demandas no campo político-pedagógico e desdobramentos na produção acadêmicocientífica.

A análise da produção sobre os dois temas deve-se à nossa compreensão de que a Educação do Campo emerge das experiências educativas do MST, das lutas por formação de professores e organização do trabalho pedagógico nas escolas públicas, da formação político-pedagógica centrada no fortalecimento da identidade da classe trabalhadora e, especialmente, das demandas por políticas públicas de acesso aos estudos da Educação Básica, passando pela Superior até a pós-graduação, bem como pela continuidade desses estudos. A Educação do Campo é a materialização das lutas dos movimentos sociais do campo, em especial do MST, na forma de políticas educacionais que se desdobram nas frentes da formação inicial e continuada de professores, criação de diversos programas governamentais e financiamento da educação e da produção científica, entre outras frentes. Nesse processo, os problemas reais são investigados cientificamente pelos próprios sujeitos dos movimentos e das lutas, e por aqueles que pertencem à classe trabalhadora e que fazem mediação político-pedagógica desde as universidades e demais instituições de educação superior. A realidade, materializada nas ações do MST, gera relações sociais, novas lutas e enfrentamentos com o Estado, expressos no Movimento Nacional de Educação do Campo, conforme Munarim (2008 e 2010).

O artigo traz resultados de nossas pesquisas de natureza documental-bibliográfica. O corpus da pesquisa bibliográfica é formado pelas teses e dissertações defendidas em programas das Ciências Humanas e da área de avaliação da Educação na CAPES (Coordenação de Aperfeiçoamento de Pessoal de Nível Superior), mediante análise dos títulos, resumos e conteúdo. O corpus documental é formado pelos conteúdos disponíveis no catálogo digital de teses da CAPES, criado em 2002, e nas bibliotecas digitais dos programas de pós-graduação, cuja portaria $n^{\circ} 13$ de criação pela CAPES data de 15 de fevereiro de 2006. Incluem-se ainda documentos fornecidos pelo Diretório de Grupos de Pesquisa do $\mathrm{CNPq}$ (Conselho Nacional de Desenvolvimento Científico e Tecnológico), que possibilitam a identificação de grupos, líderes, temas centrais de investigação e equipe de pesquisadores.

As pesquisas de natureza documental-bibliográfica, como as denominamos, têm estreita relação com a metapesquisa e superam a condição dos estudos da arte, revisão de literatura ou pesquisa de pesquisas. São investigações que permitem identificar a produção do conhecimento em seus avanços, tendências, interfaceamento temático, marcos teórico-metodológicos, presenças e ausências de objetos de investigação. Como supõe Sánchez Gamboa (2007, p. 53), “[...] todo processo de produção do conhecimento se manifesta numa estrutura de pensamento que inclui conteúdos filosóficos, lógicos, epistemológicos, teóricos, metodológicos e técnicos".

A pesquisa foi desenvolvida em oito etapas desde o levantamento bibliográfico até a análise do conteúdo, a saber: 1) delimitação do objeto, abrangência territorial e temporal; 2) definição dos documentos e fontes bibliográficas; 3) organização das informações sobre as pesquisas, tais como título, 
tipo de pesquisa, ano de conclusão e instituição; 4) levantamento dos grupos de pesquisa vinculados ao objeto investigado; 5) sistematização das informações quantitativas por regiões e instituições, objetivando identificar tendências territoriais na produção do conhecimento; 6) seleção de amostra para análise do conteúdo; 7) análise do conteúdo ou estudo sistemático do corpus bibliográfico com o foco na identificação do objeto, método, contexto social e territorial, instrumentais de coleta e análise de dados, conceitos centrais e a relação entre sujeito e objeto da pesquisa, tomando-se como referência Sánchez Gamboa (1989, 2007) e Silva e Sánchez Gamboa (2014); 8) categorização do conteúdo, evidenciando presenças e ausências de objetos investigados, tendo em mente o movimento da realidade em sua materialidade e historicidade. Essas oito etapas têm aproximação com as três grandes etapas da metapesquisa indicadas por Mainardes (2018, p. 312-313), que são: definição dos propósitos da metapesquisa e da amostra, organização e sistematização da amostra e leitura sistemática.

Compreendemos que a prática social, em perspectiva histórica, tem sido a geradora dos interesses dos pesquisadores para os problemas educacionais relacionados aos povos do campo, no contexto da reforma agrária e da agricultura familiar no Brasil. O MST, os grupos e núcleos de pesquisa das universidades e o Fórum Nacional de Educação do Campo (FONEC) são coletivos orgânicos e medidores de processos de produção de conhecimentos. A existência dos coletivos de pesquisa nas universidades propicia o avanço das pesquisas educacionais que têm como sujeitos os povos do campo e sua produção da existência em cenários de lutas cotidianas e históricas. Os espaços públicos de debate das produções acadêmicas também têm sido fundamentais no fortalecimento da produção científica. São exemplos disso as reuniões científicas da Associação Nacional de Pós-Graduação e Pesquisa em Educação (ANPEd), o Seminário Internacional de Educação do Campo (SIFEDOC), as reuniões da Associação Nacional de Política e Administração da Educação (ANPAE), dos seminários nacionais de Educação do Campo que constituem lugares coletivos de resistência e de produção/problematização de conhecimentos. Por fim, na prática social, as políticas educacionais e de financiamento de projetos de pesquisas com foco na diversidade potencializaram as pesquisas nas duas áreas investigadas.

Em nossos estudos consideramos a contradição presente na sociedade brasileira a partir de quatro pontos, explicitados em Souza (2016a): 1) a história do Brasil é marcada por lutas sociais no campo contra a exploração e a favor da reforma agrária, na perspectiva dos trabalhadores, e pela conservação da propriedade, nos interesses das empresas e latifundiários. Os dois grupos estão organizados politicamente em movimentos como o MST, por exemplo, e como a União Democrática Ruralista (UDR); 2) luta de classes que gera disputas por projetos de campo - de um lado, o campo da agricultura familiar e camponesa e, de outro, o campo do agronegócio; 3) luta pela educação escolar, que tem sido uma constante na vida dos agricultores familiares e camponeses, em meio à política de migração campo-cidade, nucleação e fechamento de escolas; 4) ao mesmo tempo que enfrentam a classe latifundiária e o próprio Estado, os movimentos sociais de trabalhadores do campo fazem articulações (e enfrentamentos) com outras entidades da sociedade civil e com o próprio Estado, para discutir e promover experiências formativas nos acampamentos e assentamentos da reforma agrária.

Em meio a essas contradições, há o Movimento Nacional de Educação do Campo, conforme análises de Munarim (2008 e 2010), que tem construído experiências formativas e produzido conhecimentos educacionais. São dezenas de livros oriundos da prática e produção coletiva do conhecimento em Educação do Campo. No ambiente universitário, os projetos vinculados a programas de fomento nacionais têm forte potencial para geração de conhecimentos coletivos a partir da ação de pesquisadores orgânicos dos movimentos sociais. Ultrapassam, portanto, a barreira do paradigma positivista na construção de conhecimentos científicos e superam os "discursos sobre o outro", em grande parte, quando são produzidos pelos próprios sujeitos da luta e da experiência coletiva. Assim, a prática social vinculada aos movimentos sociais tem sido o lócus principal dos problemas investigados nas dissertações e teses, no conjunto das relações contraditórias características das disputas por terra e por educação no Brasil.

É desse contexto histórico, marcado pela produção acadêmico-científica, que tratamos neste artigo, organizado em quatro partes. A primeira contextualiza o processo de pesquisa e os resultados do ponto de vista quantitativo, demarcando a territorialização da produção de dissertações e teses, dando 
ênfase aos aspectos histórico-sociais de que trata Sánchez Gamboa (1989, 2007). A segunda traz a análise da produção do conhecimento, apresenta os principais temas presentes nas investigações, a vertente teórica predominante nas dissertações e teses e indicativos de temas/problemas que necessitam de maior investigação no contexto do MST e da Educação do Campo. A terceira traz reflexões sobre o aspecto epistemológico, com ênfase nos elementos lógicos descritos por Sánchez Gamboa (1989, 2007), em particular os níveis técnicos, metodológicos e teóricos. A quarta parte, por fim, indica lacunas e tendências na produção do conhecimento na área.

\section{CONTEXTO DA PESQUISA: TEMPO E TERRITÓRIO DAS DISSERTAÇÕES E TESES}

A pesquisa documental-bibliográfica tem sido realizada por nós desde 2005, mediante análise de dissertações e teses defendidas nos programas de pós-graduação da área de avaliação da educação. Neste artigo, construímos o corpus bibliográfico a partir da pesquisa pautada nas palavras-chave "MST" e "Educação do Campo". Conhecendo o movimento da produção acadêmica da área e reconhecendo que a Educação do Campo tem estreita relação com os processos formativos constituídos no MST, nossa opção foi pela busca exata dos termos "MST" e "Educação do Campo". Em outros momentos investigativos, levantamos dados sobre "educação rural", "escolas rurais", "escolas no campo", "escolas do campo" e construímos debates sobre a concepção da educação rural e a concepção da Educação do Campo, publicados em Souza (2016b).

No ano de 2008, concluímos a investigação referente ao período de 1986 a 2007, ocasião em que localizamos 196 pesquisas, somadas às dissertações e teses que se dedicaram ao MST e à Educação do Campo, na área da Educação. Importante registrar que uma das primeiras pesquisas sobre MST, em Programa de Pós-Graduação em Educação, data de 1986, de autoria de Roseli Caldart, de acordo com Souza (2007). Em continuidade a essa linha de investigação, revisamos a pesquisa no ano de 2015, com levantamento bibliográfico no catálogo de teses da CAPES, englobando o período de 1986 a 2015. Essa revisão permitiu identificar 796 trabalhos que se dedicaram a investigar MST e Educação do Campo, no contexto de 99 programas de pós-graduação stricto sensu da área de educação, cujos resultados estão publicados em obra de Souza (2016a). Em muitos momentos, complementamos o levantamento bibliográfico com consulta direta aos Programas de Pós-Graduação da área de Educação e aquisição das dissertações e teses defendidas. $\mathrm{O}$ acesso ao trabalho na íntegra possibilita, a partir da lista de referências, identificar outras dissertações e teses. Criamos a dinâmica de levantamento bibliográfico pautado em elementos externos ao texto, ou seja, aqueles vinculados aos sujeitos que produziram ou avaliaram as obras. Assim, verificar o currículo Lattes dos autores, orientadores e membros de banca é fundamental para se identificarem outras dissertações e teses, complementando os dados obtidos a partir do catálogo da CAPES.

Por fim, no ano de 2019 revisitamos o conjunto de pesquisas educacionais sobre MST e Educação do Campo, a fim de comprovar as tendências teórico-metodológicas e regionais dessa produção de conhecimentos, presenças e ausências/lacunas de problemas investigados. Novamente, realizamos um minucioso levantamento no catálogo de teses e dissertações, com as palavras-chave "MST" e "Educação do Campo", e identificamos 1.310 pesquisas defendidas na grande área de Ciências Humanas e da Educação, no conjunto dos 184 programas de pós-graduação stricto sensu registrados na área de avaliação da Educação na CAPES. São 410 pesquisas sobre o MST e 900 pesquisas sobre Educação do Campo, para o período de 1986 a 2018. Esse levantamento documental não é suficiente para dizer da quantidade de trabalhos que se dedicam aos temas, havendo necessidade de leitura cuidadosa de títulos e resumos, bem como seleção de amostra para estudo do conteúdo, para se ter certeza do vínculo da pesquisa com os referidos temas.

Após análise do título e dos resumos de cada uma das 1.310 pesquisas (900 sobre Educação do Campo e 410 sobre MST), selecionamos 763 com estreito vínculo com a "Educação do Campo" e 359 sobre "MST", haja vista que alguns trabalhos apareceram na consulta geral, mas não tinham vínculos com o campo como lugar de trabalho, território da agricultura familiar e das lutas por reforma agrária. Agrupamos os dados por ano de defesa, tipo de trabalho (dissertação ou tese), instituição de defesa e eixos temáticos. Por fim, selecionamos uma amostra de $10 \%$ dos trabalhos para análise do conteúdo, 
constituindo o corpus bibliográfico, a partir do critério de predominância temática, com base nos Quadros 1 e 2 apresentados adiante neste artigo. Selecionamos pesquisas sobre prática educativa, formação de professores (Pedagogia da Terra e Licenciatura em Educação do Campo), trabalho e educação e proposta educacional do MST.

$\mathrm{Na}$ análise das pesquisas educacionais, foram considerados dois aspectos históricos: o aumento do número de programas de pós-graduação da área de avaliação da Educação e dos grupos de pesquisa na área; e a dinâmica dos coletivos diretamente ligados aos temas, a exemplo do MST e do Movimento Nacional de Educação do Campo, expresso pelo FONEC, suas lutas por reforma agrária, educação e por outro projeto de campo. Sobre os cursos de pós-graduação, o primeiro curso de mestrado em educação no Brasil data de 1966, conforme Sousa e Bianchetti (2007). No período trienal de 2007, foram registrados 78 programas de pós-graduação, conforme MEC/CAPES (2019).

No período quadrienal analisado em 2017, foram computados 172 programas de pósgraduação em educação. Em abril de 2019, o País contava com 184 programas, computando 270 cursos, sendo 133 de mestrado acadêmico, 88 cursos de doutorado acadêmico, 48 de mestrado profissional e 1 curso de doutorado profissional (MEC, CAPES, 2019). No mesmo documento está informado que, para o período de 2007 a abril de 2019, o número de programas da área da Educação quadruplicou na Região Norte (de 3 para 13), triplicou nas regiões Nordeste (11 para 34) e Centro-Oeste (7 para 25), duplicou na Região Sul (19 para 47) e aproximou-se da duplicação na Região Sudeste (38 para 73). Essa realidade tem relação com a tendência identificada em nossa pesquisa, de aumento expressivo da produção acadêmica nas regiões Norte, Nordeste e Centro-Oeste do País. Além disso, há uma dinâmica de relação entre movimentos sociais e universidades, que se soma à política de financiamentos com cotas para as regiões Nordeste, Norte e Centro-Oeste, possibilitando o aumento de projetos de pesquisa na região, bem como do número de doutores e grupos de pesquisas que se interessam pelos movimentos sociais do campo e deles participam, nas referidas regiões. As regiões Sul e Sudeste foram berço para a formação acadêmica de pesquisadores que orientam teses e dissertações sobre MST e Educação do Campo em diversas IES do Brasil. São duas regiões que continuam com os maiores números de programas de pós-graduação e, portanto, ainda figuram entre as que mais possuem IES com defesas de dissertações e teses na área estudada.

Em 88 instituições de educação superior, identificamos pesquisas sobre Educação do Campo; e em 65 instituições, sobre o MST, todas em programas de pós-graduação da área de avaliação da educação na CAPES. No contexto de ampliação dos programas de pós-graduação stricto sensu na área da educação e de emergência da Educação do Campo, a produção do conhecimento é marcada por ascendência anual, como pode ser observado nos Gráficos 1 e 2, tomando-se como referência as 359 produções sobre o MST e as 763 sobre Educação do Campo. No caso do MST, o decréscimo de uma década, visível no Gráfico 1, tem relação com a conquista de expressividade pela Educação do Campo como foco das pesquisas que analisaram formação de professores, prática educativa e organização do trabalho pedagógico em escolas localizadas em assentamentos da reforma agrária. Quando não havia o conceito de Educação do Campo, as escolas eram tratadas como sendo do MST. Assim, há uma linha tênue entre pesquisas que trataram da educação no MST e aquelas que trataram da Educação do Campo, no contexto de acampamentos e assentamentos organizados no MST, ou em contextos da agricultura familiar, de comunidades ribeirinhas, povos das florestas e povos tradicionais do campo.

\section{GRÁFICO 1 - PESQUISA EDUCACIONAL SOBRE MST}




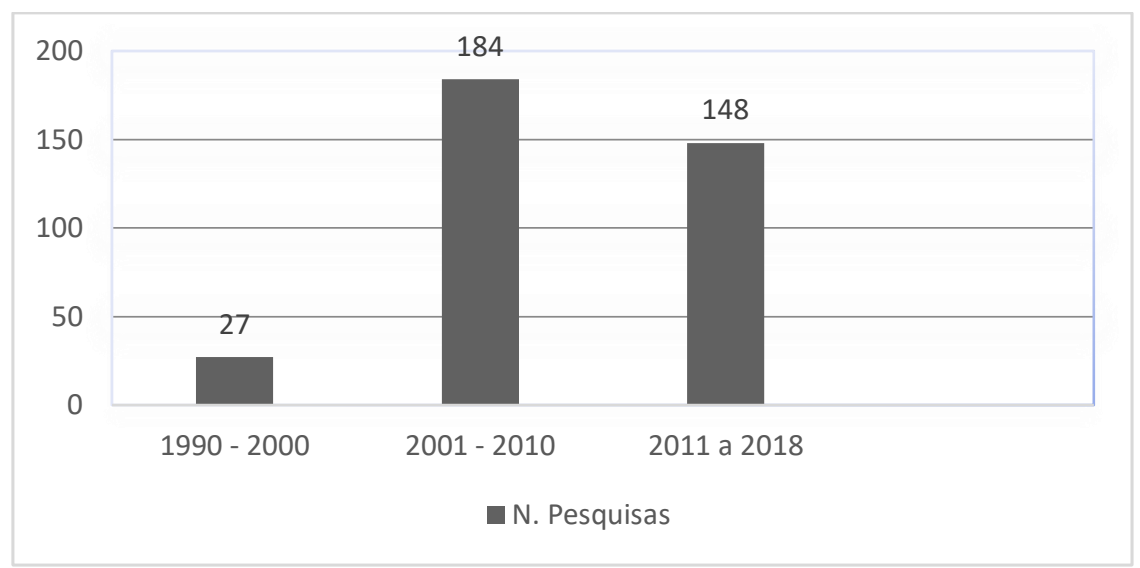

Fonte: Catálogo de Teses CAPES, outubro de 2019. Organizado: Maria Antônia de Souza, 2019.

Dentre os 359 trabalhos, 264 são dissertações e 95 são teses abordando o MST em sua relação com a educação. Das 264 dissertações, 6 foram concluídas em mestrados profissionais. Em Souza (2016a), registramos que as pesquisas sobre o MST tiveram início na década de 1980, com dois estudos defendidos na área da Educação. Ao analisarmos os trabalhos sobre o MST, constatamos que no período de 2008 a 2018 a Educação do Campo estava presente nos títulos de 40 trabalhos, evidenciando o vínculo orgânico dessa concepção com a sua materialidade de origem.

Sobre a Educação do Campo, verifica-se o aumento das pesquisas após dez anos de sua emergência, ou seja, elas têm expressividade a partir de 2009. Isso, em grande parte, deve-se aos programas governamentais da área, a exemplo do Programa Nacional de Educação na Reforma Agrária (PRONERA), de 1998, e do Programa de Apoio à Formação Superior em Licenciatura em Educação do Campo (PROCAMPO), de 2007, que geraram dezenas de estudos sobre a formação de professores, as práticas educativas e as políticas educacionais. Guardam relação com políticas de financiamento de pesquisas que articulam pós-graduação stricto sensu e Educação Básica, a exemplo do Programa Observatório da Educação, CAPES. Esse aumento das pesquisas também tem relação com o ingresso de educandos dos movimentos sociais nas universidades, que impulsionaram as pesquisas sobre a própria realidade e as lutas por educação no contexto da reforma agrária e da agricultura familiar, bem como com a ampliação do número de programas de pós-graduação nas regiões Norte e Nordeste do País.

GRÁFICO 2 - PESQUISAS SOBRE A EDUCAÇÃO DO CAMPO: 2002 A 2018 


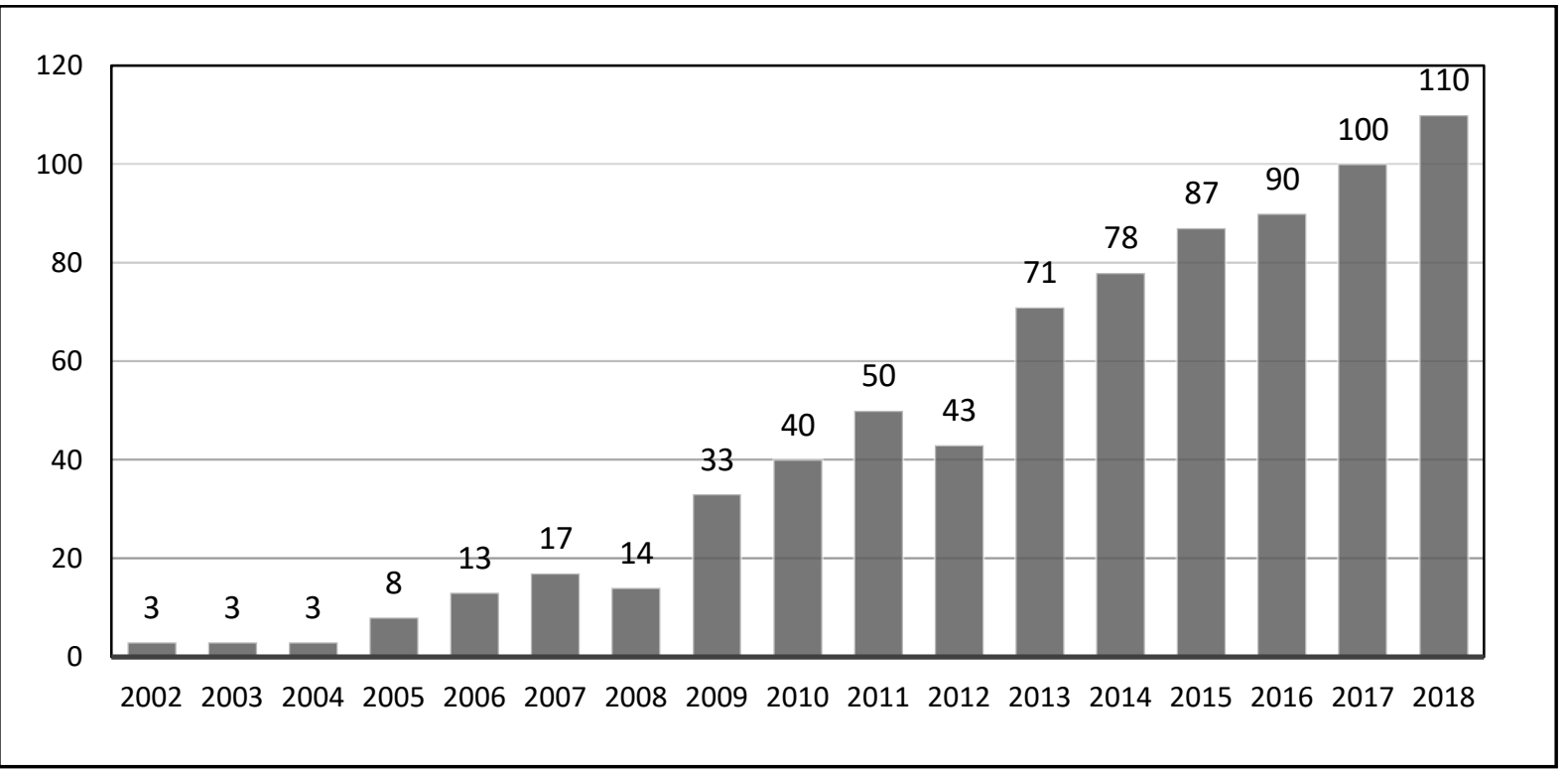

Fonte: Catálogo de Teses CAPES, outubro de 2019. Organizado: Camila Casteliano Pereira dos Santos e Maria Antônia de Souza, 2019.

Dentre os 763 trabalhos, 594 são dissertações, sendo 60 delas realizadas em Mestrado Profissional. O total de teses de doutorado é 169, sendo 120 delas produzidas no período de 2013 a 2018. Verifica-se a tendência de ampliação das teses de doutorado sobre Educação do Campo, sendo que uma parte significativa delas é fruto da continuidade dos estudos realizados no mestrado.

As experiências do PRONERA desencadearam estudos sobre Educação do Campo, políticas educacionais de formação inicial de professores, formação continuada, prática educativa, formação técnica, programas específicos para escolas multisseriadas, licenciatura específica para profissionais vinculados a escolas e processos formativos no/do campo. Momento histórico de construção de experiências coletivas de formação educacional em todo o País, mediante relações político-pedagógicas estabelecidas entre movimentos sociais e universidades, desdobrando-se em centenas de pesquisas em todas as áreas do conhecimento, em particular nas Ciências Humanas e Educação.

As instituições de realização das pesquisas estão distribuídas regionalmente, conforme disposto nos Gráficos 3 e 4.

\section{GRÁFICO 3 - REGIÕES, IES E PESQUISAS SOBRE MST}

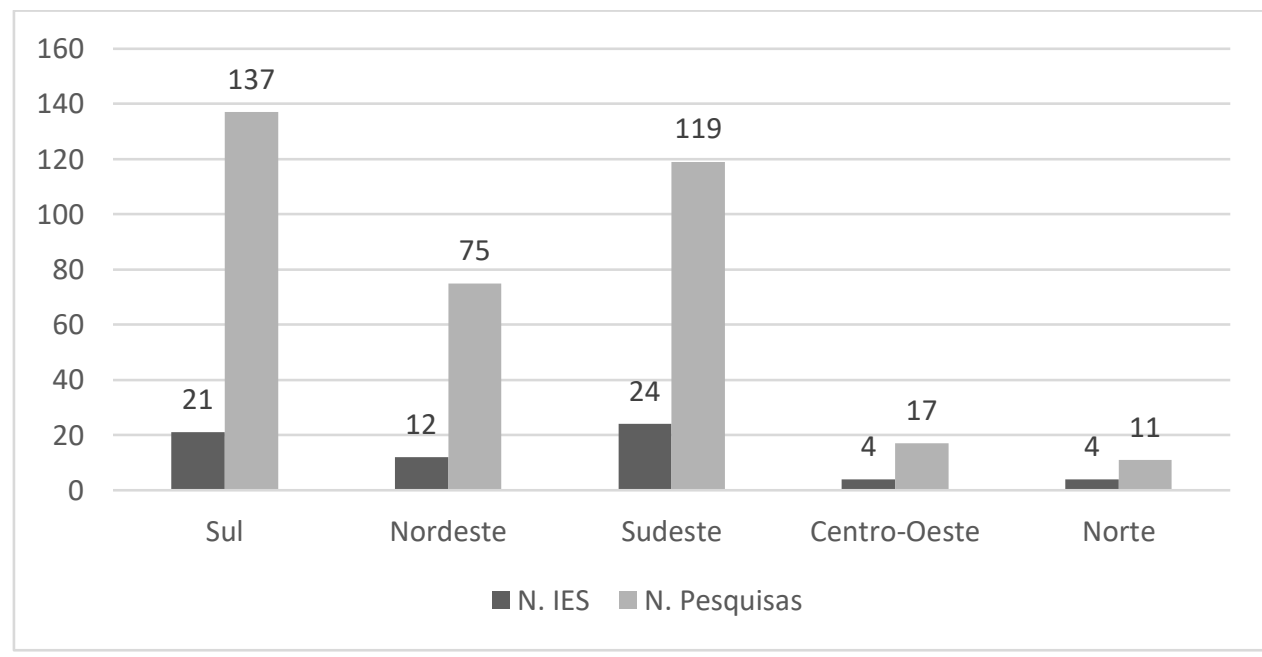

Fonte: Catálogo de teses da CAPES, outubro de 2019. Organização: A autora. 
Proporcionalmente ao número de instituições de educação superior, a Região Sul é a que mais possui trabalhos sobre o MST (6,50\%); em segundo lugar está a Região Nordeste (6,25\%), seguida da Região Sudeste (4,95\%), depois a Região Centro-Oeste (4,25\%) e, por último, a Região Norte (2,75\%). As IES com maior número de pesquisas sobre o MST são: Universidade Federal de Santa Catarina (37), Universidade Federal do Rio Grande do Sul (25), Universidade Estadual de Campinas (22), Universidade Federal de Minas Gerais (19), Universidade Federal do Ceará (18), Universidade Federal do Paraná (14), Universidade Federal de São Carlos (13), Universidade Federal da Paraíba (12), Universidade Federal do Rio Grande do Norte (12), Universidade Federal do Espírito Santo (11), Universidade Federal Fluminense (10) e Universidade Estadual de Maringá (10). As demais apresentam um total igual e abaixo de 9. A centralidade da produção está em IES da região Centro-Sul, o que se justifica pela atuação do MST nos estados do Sul e Sudeste, com os acampamentos, assentamentos e as experiências educativas iniciadas particularmente na região Sul do País, bem como pela presença do maior número de programas de pós-graduação.

\section{GRÁFICO 4 - NÚMERO DE IES COM PESQUISAS EM EDUCAÇÃO DO CAMPO POR REGIÃO}

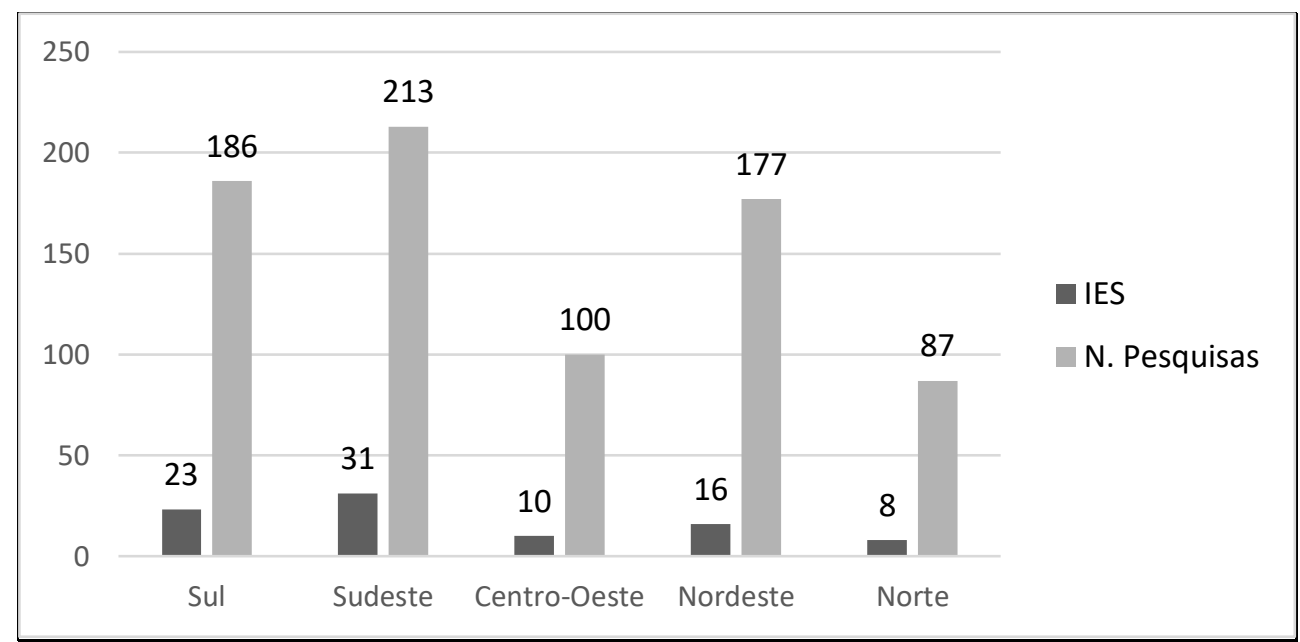

Fonte: Catálogo de teses da CAPES, outubro de 2019. Organização: A autora.

Uma primeira análise do gráfico 4 evidencia que a Região Sudeste tem o maior número de pesquisas sobre Educação do Campo, entretanto, proporcionalmente, a Região Nordeste é a que mais possui pesquisas: uma média de 11 pesquisas distribuídas por 16 IES. Em segundo lugar está a Região Norte, com a média de 10,8 pesquisas distribuídas por 8 IES. Em terceiro lugar está a Região CentroOeste, com a média de 10 pesquisas distribuídas pelas 10 IES. Em quarto está a Região Sul, com uma média de 8 pesquisas distribuídas em 23 IES. Em quinto lugar está a Região Sudeste, com uma média de 6,8 pesquisas, distribuídas por 31 IES. Assim, quantitativamente, a Região Sudeste tem o maior número de pesquisas, porém, proporcionalmente ao número de IES com pesquisas na área, verifica-se a tendência de crescimento das pesquisas nas regiões Nordeste, Norte e Centro-Oeste. No ano de 2016, a região Centro-Sul detinha 61,06\% das pesquisas defendidas sobre MST e Educação do Campo, diminuindo para $52 \%$ no levantamento de 2019. As regiões Nordeste, Norte e Centro-Oeste abarcavam 39\% das pesquisas em 2016 e aumentaram para 48\% em 2019, contabilizadas as defesas ocorridas até o ano de 2018.

A concentração das pesquisas sobre Educação do Campo é identificada nas seguintes instituições de Educação Superior: Universidade de Brasilia (46), Universidade Federal de Minas Gerais (38), Universidade Federal do Pará (38), Universidade Tuiuti do Paraná (33), Universidade Federal de São Carlos (32), Universidade Federal da Bahia (24), Universidade Federal do Paraná (24), Universidade Federal do Espírito Santo (24), Universidade Federal de Santa Catarina (24), Universidade Federal de Viçosa (24), Universidade Federal do Rio Grande do Norte (23) e Universidade Estadual da Bahia (20). 
As demais IES possuem entre 1 e 20 trabalhos defendidos, e dentre elas estão a Universidade Estadual do Pará (13), Universidade Estadual de Roraima (12), Universidade Federal do Amazonas (11), Universidade Federal de Sergipe (15), Universidade Estadual de Feira de Santana (15), Universidade Federal de Juiz de Fora (14), Universidade Federal do Rio Grande do Sul (17), Universidade Estadual do Oeste do Paraná (15), Universidade Federal de Mato Grosso (17), Universidade Estadual de Mato Grosso (14). Há presença de dissertações em Educação do Campo oriundas de programas profissionais, tais como o da Universidade Estadual de Santa Cruz/BA e o da Universidade Estadual de Roraima.

Portanto, identifica-se a tendência no crescimento das pesquisas em Educação do Campo fora do eixo Centro-Sul do País, embora a maior parte dos programas da área da Educação esteja concentrada nele. As marcas da agricultura familiar e camponesa são expressivas em todo o Brasil, particularmente nas três regiões em que tem havido ampliação das pesquisas. Nelas, também, houve crescimento dos grupos de pesquisas e dos programas governamentais vinculados ao PRONERA e PROCAMPO, com instituições liderando projetos-piloto e, posteriormente, consolidando cursos regulares em diversas áreas do conhecimento para beneficiários da reforma agrária, agricultores familiares, ribeirinhos, povos das florestas, entre outros.

Um levantamento de dados junto ao Diretório de Grupos do CNPq, pela palavra exata "Educação do Campo", no ano de 2019, identificou 253 grupos de pesquisa em todas as áreas do conhecimento. Analisando os resumos dos grupos, foram encontrados $123 \mathrm{com}$ foco voltado para Educação do Campo. Territorialmente, 37 grupos estão em instituições públicas da Região Nordeste, 29 na Região Norte, 26 na Região Sul, 24 na Região Sudeste e 7 na Região Centro-Oeste. Quando a consulta é realizada com a palavra-chave "movimentos sociais do campo", são identificados 18 grupos de pesquisa, nas diversas áreas do conhecimento, sendo 6 grupos da Educação. Foram localizados 2 grupos na busca pela palavra "Movimento dos Trabalhadores Rurais Sem Terra".

O grupo de pesquisa exerce influência na formação de novos pesquisadores e no fortalecimento dos objetos de investigação articulados à prática social. O que se verifica é o crescimento dos grupos de pesquisa em torno do tema "Educação do Campo", que, por sua vez, agrega eixos de investigação tais como: prática educativa, formação de professores, cursos de Pedagogia da Terra e Licenciatura em Educação do Campo e, também, Escola Pública e diversos programas governamentais da Educação do Campo.

O número de grupos de pesquisa que se preocupam com a Educação do Campo tem sido ampliado em todas as regiões. Essa produção é fruto da vinculação dos pesquisadores com os movimentos sociais do campo e com o debate do projeto popular para o Brasil, assim como das políticas educacionais em Educação do Campo que possibilitaram dezenas de processos formativos iniciais e continuados, a partir da relação entre universidade e movimentos sociais. Alguns pesquisadores vêm da militância em movimentos sociais, outros constituíram-se como militantes a partir de projetos de pesquisa e de extensão desenvolvidos em parcerias entre coletivos pertencentes a universidades e os coletivos dos movimentos sociais.

A dinâmica societária inquieta alguns pesquisadores que se desafiam a compreender a "história em movimento". Na Região Nordeste, em função do fortalecimento de grupos de pesquisa, em especial na UFC/Fortaleza, UFRN, UFPB e UFBA, tem havido um crescimento do número de pesquisas. $\mathrm{Na}$ Região Norte, o estado do Pará tem representatividade. O pesquisador Salomão Hage tem sido expoente na coordenação de grupo de pesquisa e orientação de alunos da pós-graduação em educação, na temática da Educação do Campo, movimentos sociais do campo e escolas multisseriadas. A UnB na Região Centro-Oeste tem expressividade na produção de teses e dissertações, haja vista que é uma das universidades pioneiras na coordenação de projetos em educação e movimentos sociais do campo, sendo Mônica Molina uma das expoentes na área. Na Região Sul, a UFSC tem destaque com as orientações de Célia Vendramini, Antonio Munarim e Sonia Beltrame. O programa de pós-graduação da Universidade Tuiuti do Paraná tem expressividade nas pesquisas educacionais que se articulam à Educação do Campo, haja vista a existência de Núcleo de Pesquisa na área. A Universidade Federal do Paraná tem expressividade com estudos sobre escolas públicas, currículo e materiais didáticos. Na Região Sudeste, a UFMG destaca-se a partir das orientações de Antônio Júlio Menezes Neto e Maria Isabel Antunes-Rocha, 
com ênfase em aspectos vinculados ao MST e à Licenciatura em Educação do Campo, formação de professores.

Em síntese, são duas temáticas que têm conquistado espaço acadêmico, nos programas de pós-graduação stricto sensu, e evidenciado problemas e experiências político-pedagógicas objetivando sua superação. Do ponto de vista da análise de elementos histórico-institucionais, constatamos a emergência e o fortalecimento das pesquisas nas regiões Norte, Nordeste e Centro-Oeste, assim como de grupos de pesquisas centralizados em três IES dessas regiões: UFPA, UFPB e UFMT. Durante as análises dos títulos e resumos das pesquisas, também foi possível perceber a presença marcante dos temas formação de professores, prática educativa e política educacional, com evidência para os segmentos sociais ainda "invisibilizados" nas pesquisas, a exemplo da juventude, crianças, idosos e pessoas deficientes e/ou com necessidades especiais.

\section{A PRODUÇÃO DO CONHECIMENTO EDUCACIONAL: MST E EDUCAÇÃO DO CAMPO}

A produção do conhecimento sobre o MST em sua relação com a educação acontece no movimento de luta pela terra, reforma agrária, projeto popular de país e por políticas públicas, e se concentra em seis grandes eixos temáticos: proposta educacional do MST, processos formativos de educadoras e educadores, organização do trabalho pedagógico, políticas públicas, trabalho e educação e formação política/identidade política. Os segmentos sociais da classe trabalhadora presentes em algumas pesquisas são crianças, jovens, adultos e pessoas com deficiências ou necessidades especiais. Nesse contexto, verifica-se que as pesquisas sobre o MST em maior número problematizam formação de professores, prática educativa e a organização do trabalho pedagógico na escola. O central é investigar o acesso à escola e o direito a uma formação de "qualidade", que se expressa em relações adequadas de trabalho para os professores, materiais didáticos, política salarial, vínculo entre os conteúdos curriculares e o processo de luta por reforma agrária no País e o modo de vida dos povos do campo. A relação trabalho e educação tem expressividade, especialmente nas pesquisas com o método materialista histórico dialético. São estudos que tomam como referência o trabalho como princípio educativo, as cooperativas organizadas nos assentamentos da reforma agrária, a formação técnica e profissional de jovens e adultos, reflexões sobre trabalho, Educação do Campo e politecnia e, nos últimos anos, estudos sobre agroecologia.

O quadro 1 traz o conjunto de temas de presença expressiva nas pesquisas localizadas a partir do descritor MST. Eles foram classificados segundo aproximação temática, porém toda classificação é provisória e pode ser aprimorada. A maior parte dos trabalhos tem dois ou mais temas que se entrelaçam como objetos ou como contexto da investigação. A maioria dos trabalhos analisa a proposta educacional do MST nas práticas do próprio movimento ou das escolas públicas. O contexto/lugar predominante nas pesquisas é o movimento social, a escola pública, a comunidade e as universidades. Os objetos predominantes são educação do MST, formação de professores, prática educativa e políticas públicas educacionais. A Educação do Campo foi classificada como um tema no contexto das pesquisas sobre o MST para se referir a pesquisas que objetivaram traçar a trajetória, identidade, construção do Movimento de Educação do Campo etc.

\section{QUADRO 1 - TEMAS PRESENTES NAS PESQUISAS SOBRE MST}

\begin{tabular}{|l|l|}
\hline Temas & Presença \\
\hline $\begin{array}{l}\text { Proposta educacional do MST. Educação como estratégia política. Projeto político } \\
\text { pedagógico do MST. Emancipação humana e processos educativos. }\end{array}$ & 38 \\
\hline $\begin{array}{l}\text { Processos formativos de educadoras e educadores. Pronera. Pedagogia do MST. } \\
\text { Licenciatura em Educação do Campo (Ledoc). Relação com universidades. } \\
\text { Pedagogia da Terra. }\end{array}$ & 38 \\
\hline $\begin{array}{l}\text { Organização do trabalho pedagógico. Escola do MST. Construção curricular. } \\
\text { Projeto político pedagógico. Complexos de estudo. }\end{array}$ & 34 \\
\hline Trabalho docente. Prática educativa. Materiais didáticos. & 31 \\
\hline
\end{tabular}




\begin{tabular}{|l|l|}
\hline $\begin{array}{l}\text { Trabalho e Educação. Formação pelo Trabalho. Trabalho e Cooperação. Trabalho, } \\
\text { educação e emancipação. }\end{array}$ & 29 \\
\hline Educação do Campo, políticas públicas. & 27 \\
\hline Formação política, identidade, experiência educativa e consciência de classe. & 26 \\
\hline Educação de jovens e adultos. & 18 \\
\hline Infância, Educação infantil, sem terrinha. & 15 \\
\hline $\begin{array}{l}\text { Escola itinerante: relação com governos, práticas de leitura, trabalho como } \\
\text { princípio educativo. }\end{array}$ & 14 \\
\hline $\begin{array}{l}\text { Juventude: identidade, cultura digital, participação política, televisão e evasão de } \\
\text { jovens do campo. }\end{array}$ & 12 \\
\hline Formação profissional: tecnologias, agroecologia, gestão de cooperativas. & 12 \\
\hline Mística, experiência coletiva com manifestação artística e teatro. & 9 \\
\hline Trabalho, educação e relações de gênero. & 9 \\
\hline Educação popular. & 7 \\
\hline Cultura corporal, corporeidade. & 6 \\
\hline Alfabetização, práticas de leitura, letramento. & 6 \\
\hline $\begin{array}{l}\text { Outros temas: etnomatemática, educação ambiental, práticas de saúde, inclusão, } \\
\text { religião, lazer, pensadores socialistas, empresariamento da educação, ciclos de } \\
\text { formação humana. }\end{array}$ & 28 \\
\hline Total & 359 \\
\hline
\end{tabular}

Organização: A autora, 2019.

O aumento do número de pesquisas na área tem relação, como já exposto, com as lutas sociais e com o protagonismo da sociedade civil nos enfrentamentos feitos com governos, visando a construção de políticas públicas demandadas pelos coletivos e que eles sejam sujeitos da ação e das políticas. As pesquisas têm estreita relação com a história dos povos do campo no Brasil, que é de resistência, de lutas, enfrentamentos político-militares e criação de alternativas. O movimento do real tem sido motor para a emergência de grupos de pesquisas, cujas construções teóricas são subsidiadas no movimento histórico da sociedade, dos interesses de classe, da contradição capital x trabalho, da educação como formação humana em meio a ideologias e disputas por hegemonia. A pesquisa sobre MST é referenciada na materialidade da vida nos movimentos sociais, nos assentamentos, acampamentos, comunidades ribeirinhas, povos das florestas, nas escolas públicas, nos coletivos de formação e estudos construídos com as universidades que possuem grupos comprometidos com os interesses da classe trabalhadora.

Há um importante conjunto temático emergente nas pesquisas sobre o MST, que são a Educação do Campo e as políticas públicas. Nele, o debate vincula currículo, alfabetização, letramento, formação profissional, educação infantil, educação de jovens e adultos, a escola itinerante do MST, a relação entre movimentos sociais e Estado e governos, e pesquisas que estudam as ideias de pensadores socialistas. São pesquisas que têm como contexto/lugar de pesquisa os assentamentos, acampamentos e o envolvimento com programas governamentais como o PRONERA, PROJOVEM CAMPO e o PROCAMPO. Tratam de processos formativos desenvolvidos com jovens e adultos da agricultura familiar ou beneficiários da reforma agrária.

Nesse conjunto de produção, encontram-se as dissertações e teses defendidas após 2008, ou seja, as que foram produzidas nos dez anos que se seguiram à emergência da Educação do Campo. Elas indagam a construção de políticas públicas e os enfrentamentos entre movimentos sociais e governos, bem como as disputas políticas que dão visibilidade aos interesses do capital em oposição aos interesses dos povos trabalhadores do campo. Tomam como referência os documentos dos coletivos nacionais do MST e da Educação do Campo, seus relatórios e manifestos produzidos durante os encontros nacionais, como os de 1998 e 2004, Conferência Nacional por Educação do Campo, e documentos governamentais como as diretrizes operacionais da educação básica nas escolas do campo de 2002, as diretrizes complementares de 2008, o decreto presidencial n 7.352 de 2010 e as diretrizes de governos estaduais. 
Há potencial para a investigação de outros temas, ainda incipientes ou ausentes nos trabalhos, como sexualidade, juventude rural, envelhecimento, relações de gênero, educação especial/ inclusão, a relação escola-família, educação ambiental/sustentabilidade, agroecologia como matriz pedagógica, educação infantil, educação popular, educadores/pensadores que fundamentam discussões pedagógicas, políticas e teóricas no movimento social.

Sobre a produção do conhecimento em Educação do Campo, o Quadro 2 apresenta os temas predominantes, com referência nos títulos e resumos dos 763 trabalhos.

\section{QUADRO 2 - PESQUISAS EM EDUCAÇÃO DO CAMPO}

\begin{tabular}{|c|c|}
\hline Temas & $\begin{array}{l}\text { Total de } \\
\text { Pesquisas }\end{array}$ \\
\hline $\begin{array}{l}\text { Escolas públicas: organização do trabalho pedagógico, multissérie, práticas } \\
\text { artísticas, tempo integral, formação integral, relação escola rural e escola da cidade, } \\
\text { práticas agroecológicas, complexos de estudo, ciclos de formação, biblioteca escolar, } \\
\text { avaliação, fechamento/nucleação e impactos na prática educativa. }\end{array}$ & 160 \\
\hline $\begin{array}{l}\text { Políticas públicas: educação superior, Projovem campo, Pronera, Procampo, } \\
\text { Ledoc, transporte escolar, Escola da Terra, PNLD-Campo, Pronatec, Pronacampo, } \\
\text { Programa Mais Educação, Parfor, PNE, financiamento da educação, Proeja, } \\
\text { políticas municipais de Educação do Campo, Escola Ativa, Ensino Médio. Relação } \\
\text { universidade e Educação Básica. Projeto político pedagógico. }\end{array}$ & 154 \\
\hline $\begin{array}{l}\text { Currículo - Escolas públicas: saberes docentes, saberes culturais, cadernos } \\
\text { didáticos, livros didáticos, etnomatemática, complexos de estudo, conteúdos } \\
\text { específicos: História, Geografia, Química, Educação Física, Ciências, práticas } \\
\text { interdisciplinares. Negro na política curricular da Educação do Campo. }\end{array}$ & 45 \\
\hline $\begin{array}{l}\text { Formação de professores (educadoras e educadores): identidade docente, } \\
\text { Pedagogia Socialista, Pedagogia da Terra, pesquisa nos processos formativos, } \\
\text { formação continuada, Escola Ativa, Pró-letramento, formação para Eja. } \\
\text { Licenciatura em Educação do Campo. }\end{array}$ & 155 \\
\hline $\begin{array}{l}\text { Prática Docente, práxis pedagógica, prática educativa com uso livro didático, } \\
\text { narrativas sobre práticas educativas, saberes docentes e práticas educativas. Práticas } \\
\text { de alfabetização, jogos. }\end{array}$ & 34 \\
\hline Pedagogia da Alternância, concepção de formação em alternância. & 30 \\
\hline $\begin{array}{l}\text { Educação infantil, infância, políticas para educação infantil, saberes docentes, } \\
\text { apropriação da escrita por crianças, formação de professores, sem terrinha. }\end{array}$ & 30 \\
\hline Educação do Campo - MST. Escola itinerante. Práxis formativa no MST. & 40 \\
\hline Educação ambiental, currículo, prática pedagógica, crenças religiosas. & 21 \\
\hline $\begin{array}{l}\text { Juventude camponesa, formação política, educação popular, educação financeira } \\
\text { de jovens campesinos. }\end{array}$ & 19 \\
\hline $\begin{array}{l}\text { Trabalho como princípio educativo, educação profissional e politecnia, educação, } \\
\text { trabalho e ideologia. }\end{array}$ & 19 \\
\hline Educação de jovens e adultos, formação de professores, currículo. & 15 \\
\hline Mulheres: escolarização, trajetórias, reforma agrária, direitos. & 11 \\
\hline Formação profissional, Agroecologia. & 10 \\
\hline Questões epistêmicas da Educação do Campo & 8 \\
\hline Corpo, corporeidade, arte-linguagem. & 6 \\
\hline Educação popular e Educação do Campo. & 5 \\
\hline Educação especial, inclusão educacional, interfaces com Educação do Campo. & 8 \\
\hline Tecnologias digitais, comunicação. & 5 \\
\hline Saberes culturais, modos de vida, linguagem dos educandos. & 5 \\
\hline Gerações, economia solidária e estudo psicossocial da Educação do Campo. & 3 \\
\hline Total & 763 \\
\hline
\end{tabular}


Organização: A autora, 2019.

Os estudos da Educação do Campo são marcados por análises conjunturais e estruturais da sociedade brasileira. Mais do que descrever fenômenos, há preocupação em compreender a origem histórica, as contradições e as possibilidades de transformação e superação da realidade desigual que marca a sociedade no Brasil. Destacam-se as pesquisas que tecem análises críticas da realidade educacional contemporânea e aquelas que fazem análises críticas das pedagogias subsumidas ao universo ideológico neoliberal e pós-moderno. No entanto, há ainda outro tipo de pesquisa: aquelas que dão atenção à totalidade "campo" e às suas contradições, bem como indicam caminhos e rumam para a superação das tensões e enfrentamentos entre capital e trabalho.

Teses e dissertações dão atenção à realidade contraditória presente nas escolas públicas e mostram a fragilidade na apropriação das políticas de Educação do Campo. Os trabalhadores da educação, os professores das escolas do campo (estaduais e municipais), por exemplo, criam e participam de espaços coletivos que problematizam a realidade da escola pública, o campo, a política pública e a Educação do Campo. Cabe destacar que esses trabalhadores, ainda que de forma dispersa, são sujeitos da construção de um conhecimento "novo". A face nova reside no fato de que eles sentem a necessidade de problematizar a própria prática educativa, no contexto de comunidades organizadas politicamente, e de registrar essas problematizações. A própria dinâmica social na comunidade exige que o professor, a professora, o educador, a educadora interroguem a prática. Existem estados em que essa dinâmica formativa está mais intensa, há outros estados que sequer a têm, e há municípios que nem sabem da existência da Educação do Campo, assim como há outros que já intensificam as discussões sobre as políticas públicas da educação. As dissertações e teses têm permitido constatar a realidade em movimento e os avanços nas escolas que se inserem em comunidades organizadas politicamente e a dificuldade de apropriação da concepção e política de Educação do Campo entre os povos com frágil organização política, sob determinação de equipes pedagógicas que, às vezes, se apropriam da linguagem da Educação do Campo, porém não compreendem a sua lógica e seus fundamentos históricos.

Nesse movimento de produção do conhecimento, emerge um espaço de visibilidade, reconhecimento e sociabilidade acadêmico-científica, movido pela relação coletivos de universidades e dos movimentos sociais do campo, águas e florestas. Trata-se do espaço coletivo como lugar de divulgação e produção de conhecimento. Nele destacam-se os seminários de pesquisa em Educação do Campo e os espaços construídos nos eventos nacionais da área da educação para debate dos estudos/problemas dessa área em ascensão nas Ciências Humanas.

A produção do conhecimento oriunda das experiências entre movimentos sociais e universidades tem mostrado a força do trabalho coletivo e da luta pela recriação do trabalho camponês, do modo de vida e produção sustentáveis socioambientalmente. Do ponto de vista da produção coletiva, vale destacar o Seminário Nacional de Pesquisa em Educação do Campo, iniciado em 2005, que teve a sua primeira versão internacional em 2010 e tem-se constituído em espaço nacional de divulgação e de debate das pesquisas sobre Educação do Campo no Brasil, particularmente aquelas que estão vinculadas ao PRONERA, à SECADI (Secretaria de Educação Continuada, Alfabetização, Diversidade e Inclusão) e ao PROCAMPO.

No ano de 2010 foram apresentados, nesse seminário, cerca de 190 trabalhos sobre Educação do Campo, agrupados nos cinco eixos que integraram o evento (chamados Círculos de Produção do Conhecimento: 1. Agroecologia, soberania alimentar e Educação do Campo; 2. Formação de Educadores; 3. Educação Escolar no Campo; 4. Políticas de Educação Superior no Campo; 5. Educação do Campo, Movimentos Sociais e Políticas Públicas). Muitos dos trabalhos são produto de experiências coletivas e são também produções coletivas, coautorias entre educandos e educadores vinculados aos programas governamentais (Pronera e Procampo) que emergiram da luta dos movimentos sociais.

São temas que têm aproximação com o exposto nos Quadros 1 e 2 sobre a produção do conhecimento sobre o MST e a Educação do Campo, cuja visibilidade é ampliada nos seminários da própria área, que, por sua vez, fortalecem os grupos de pesquisa emergentes nas instituições de educação superior. 
Não podemos deixar de mencionar que o momento político atual (2016 a 2018) tem sido de fortalecimento do debate sobre processo de trabalho, paradigmas de campo (capitalismo agrário e questão agrária) e a educação dos trabalhadores, desde reivindicações e proposições que surgem ou são mediadas por eles. Tem sido um momento de críticas às políticas de empresariamento da educação e aos cortes orçamentários nos programas da Educação do Campo e da agricultura camponesa e familiar. Começam a surgir os trabalhos que discutem empresariamento da educação, disputas políticas materializadas na escola pública, mediante projetos de interesse do capital que, por meio de parceria com o poder executivo local, interferem na prática pedagógica, como se fossem materiais de apoio didático.

Em meio ao avanço da Educação do Campo como concepção originária da prática dos movimentos sociais do campo, em particular do MST, emergem as disputas políticas em torno do conceito e das experiências a ela vinculadas. Há um grupo de pesquisa dedicada à compreensão epistemológica da Educação do Campo. As teses provocadoras desse tema são de autoria de Oliveira (2008), que questiona as bases filosóficas e epistemológicas de projetos de Educação do Campo, defendendo que há projetos que se aproximam muito mais do ecletismo pós-moderno do que do campo marxista. Aproximando-se dessa análise, Marilsa Souza (2010) tece críticas à Educação do Campo no Brasil, a partir de sua investigação com o método materialista histórico-dialético, e afirma que:

(...) as pedagogias defendidas pelo MST que fundamentam a proposta do Movimento Nacional Por uma Educação do Campo são heterogêneas, um aglomerado eclético que tenta unir o pensamento cristão e as concepções fenomenológicas da educação popular, fundadas especialmente nas pedagogias de Paulo Freire e nas produções de educadores soviéticos. Um ecletismo pedagógico que não possibilita a união da teoria e da prática - união que se traduz na transformação social. (p. 364-365)

Em contraposição aos estudos de Oliveira (2008) e Marilsa Souza (2010), a tese de Ghedini (2015, p. 332), também de natureza materialista histórico dialético, com fundamentos em Marx, Gramsci e Thompson, salienta que a Educação do Campo “(...) produziu-se como um fenômeno social e educacional que engendra o projeto educativo dos Movimentos Sociais "fazendo-se" na materialidade de suas referências formativo-educativas". Destaca a experiência de sujeitos concretos pertencentes a um projeto contra-hegemônico de país, em meio a lutas e disputas de espaço do Estado. Apresenta uma análise sobre a institucionalização da Educação do Campo como "movimento", que pode ser armadilha ou possibilidade, cujas "referências históricas produzidas potencializa o lançar-se aos desenlaces da atualidade do projeto histórico". (p. 333).

Soma-se a essas pesquisas a tese de Albuquerque (2011), pautada no materialismo histórico dialético, que investigou 433 dissertações e teses sobre educação rural e Educação do Campo e identificou que metade das pesquisas analisadas se apoia no "pragmatismo", algo que considera prejudicial à formação da classe trabalhadora. Um diferencial na pesquisa de Albuquerque é que ela analisou trabalhos que trataram da escola rural, educação rural e Educação do Campo, num período em que os trabalhos na área da Educação do Campo eram reduzidos.

Essas quatro teses auxiliam na compreensão da construção epistemológica da Educação do Campo e permitem afirmar que o seu movimento tem gerado análises divergentes no que diz respeito à construção da consciência de classe e análises convergentes no que tange ao reconhecimento dos projetos educacionais construídos na prática social, embora os seus desdobramentos sejam questionados pelos pesquisadores. Ghedini (2015) mostra-se otimista em relação aos potenciais da Educação do Campo, a partir dos referenciais históricos dos Movimentos Sociais, embora interrogue os trajetos da institucionalização.

Do ponto de vista teórico-metodológico, grande parte das investigações toma como referência o conceito de movimento social numa perspectiva histórica e de classe social. Da mesma forma, o conceito de Educação do Campo é localizado no conjunto de experiências coletivas dos movimentos sociais do campo. Grande parte das pesquisas fundamenta-se no materialismo histórico dialético para compreender contradição, prática social, hegemonia, educação, escola, projeto político, política educacional, formação política, ideologia, relação entre Sociedade e Estado, entre outros temas. 
Há pesquisas que informam a fundamentação no método materialista histórico dialético, particularmente no mestrado, porém apresentam dificuldades na operacionalização das categorias do método e do objeto.

As experiências da Educação do Campo têm colocado em questão as ruralidades e diversidades socioculturais que marcam o território brasileiro e o conjunto de povos do campo que foram historicamente secundarizados ou marginalizados na história do País. A partir do reconhecimento da ruralidade territorial em função das experiências socioculturais, da densidade demográfica, das características espaciais e ambientais, coloca-se em evidência a política educacional local, a realidade do fechamento e nucleação de escolas, bem como a política do transporte escolar. Acima de tudo, coloca-se em interrogação o projeto político-econômico que marca e demarca o desenvolvimento do campo no Brasil. E, ainda, colocam-se em análise os processos de apropriação da política de Educação do Campo nas instituições escolares. As pesquisas que enfatizam escola pública, prática educativa e o cotidiano escolar tendem a fazer aproximações com perspectiva teórica da cultura escolar e perspectivas do campo fenomenológico.

As denúncias feitas pelos coletivos do movimento nacional da Educação do Campo podem gerar modificação do ordenamento jurídico, a exemplo do artigo 28 da Lei 9.394/96, que teve o parágrafo único acrescido pela Lei n 12.960 de março de 2014 - parágrafo este que tem o intuito de intimidar o processo de fechamento de escolas no campo, haja vista que dispõe sobre a necessidade de participação da comunidade e realização de diagnóstico por parte do município, antes de se fecharem escolas e para evitar o fechamento delas. Por sua vez, as investigações sobre o fechamento de escolas levam ao reconhecimento da realidade do agronegócio no campo, haja vista que plantações monocultoras, a exemplo do pinus e soja, contribuem para o aumento de localidades com baixa densidade demográfica e que ensejam atenção dos poderes públicos na efetivação dos direitos sociais. A esse respeito, acrescentamos ao conjunto de pesquisa a dissertação de Pereira (2017), que trata da política de fechamento de escolas no campo, nos municípios da Região Metropolitana de Curitiba. A pesquisadora identifica elementos estruturais e conjunturais que envolvem o fechamento e nucleação de escolas no campo, bem como destaca a organização de comunidades e suas lutas pela permanência da escola no campo.

As pesquisas têm mostrado que a Educação do Campo coloca em evidência a força do capital no território brasileiro via ação de grandes grupos econômicos e, ao mesmo tempo, constrói frentes de formação de pessoas que se interessam em construir o projeto de campo sustentável ambiental, cultural, social e economicamente. É importante reconhecer que as práticas construídas no movimento nacional da Educação do Campo têm gerado mudanças na academia, do ponto de vista da abertura de cursos de interesse dos povos do campo, bem como do ponto de vista da lógica investigativa. Essas mudanças são pequenas diante do complexo contraditório que marca a história do campo brasileiro e a história da relação trabalho e capital no campo.

\section{A LÓGICA DAS PESQUISAS: NÍVEL TÉCNICO E TEÓRICO}

As dissertações e teses são construídas sob um determinante histórico importante, que é a instituição onde são realizadas. Há três tendências nessa linha, a saber: 1) pesquisas realizadas em instituições que são pioneiras na pós-graduação em educação, a exemplo da UNICAMP, UFSCar, UFSC e UFRGS, e que possuíam grupos de pesquisa interessados no debate mais geral da educação e outros ligados aos estudos de movimentos sociais e, neles, os rurais. Essas instituições foram precursoras na orientação de trabalhos sobre Educação e/no MST. Delas emergiu um grupo de pesquisadores que demarca a segunda tendência na área; 2) pesquisas realizadas em instituições que têm programas jovens de pós-graduação em educação e grupos mais jovens ainda em Educação do Campo, como é o caso da UERR, UNEMAT, UNIOESTE, UFMT, UFT, UFPA, UnB, UEPA, entre outras. No período de 2018, destacaram-se instituições federais de ensino e programas de pós-graduação em educação recentes nos estados do Centro-Oeste, Norte e Nordeste; 3) a presença das pesquisas em instituições que firmaram parceria com o MDA/INCRA/PRONERA para realização de projetos com os povos do campo, a exemplo da UnB, UFMG, UFSC, UFPB, UFPA, UFPR, UFS, entre outras. Nessas IES, constata-se a 
expressividade de pesquisas em Educação do Campo, decorrente das relações entre os coletivos institucionais de pesquisa e os movimentos sociais do campo, e das parcerias entre as IES, INCRA/PRONERA ou MEC/SECADI/PROCAMPO, especificamente com cursos de Pedagogia da Terra e Licenciatura em Educação do Campo.

A crescente produção de dissertações e teses em Educação do Campo tem, portanto, relação com os resultados do PRONERA, conforme apontado pela II Pesquisa Nacional de Educação na Reforma Agrária (2015). Essa pesquisa identificou a realização de 320 cursos pelo PRONERA, no período de 1998 a 2011, envolvendo 82 instituições. Foram 167 cursos de Educação de Jovens e Adultos de nível fundamental, 9 cursos de nível médio e 54 cursos de nível superior. No referido período, foram identificadas 260 dissertações de mestrado, 63 teses de doutorado e 174 monografias sobre o PRONERA. Somando-se produções em vídeos, apostilas, textos, músicas, artigos etc., totalizam-se 5.920 produções. Esses dados permitem afirmar que o Movimento Nacional de Educação do Campo tem exercido um papel fundamental na ampliação do olhar para o campo, para o processo de escolarização dos povos do campo e para as lutas protagonizadas pelos povos do campo, das florestas e das águas. É dessa forma que a educação e os movimentos sociais do campo, nas condições existenciais/materiais da vida, geram objetos de investigação educacional.

A política educacional conquistada a partir das lutas dos movimentos sociais, em contexto contrário, gera novas demandas e movimento de grupos de pesquisa nas universidades e, com isso, a ampliação dos estudos comprometidos com a transformação social e que tomam como referência a realidade em movimento, em contradição e em disputas políticas.

Sobre a lógica dessas pesquisas, do ponto de vista técnico, como propõe Sánchez Gamboa (1989, 2007), calculamos que 95\% das produções trabalham com procedimentos de coleta e análise de dados centralizados na abordagem qualitativa. Utilizam técnicas tais como entrevista, observação, grupo focal, questionário, narrativa, história de vida, vivência em comunidade e análise de discurso. Aproximadamente $5 \%$ das pesquisas são do tipo documental ou de natureza bibliográfica, sem a realização de trabalho de campo. A busca pela compreensão do movimento do real é marca nas pesquisas sobre o MST e a Educação do Campo. Do ponto de vista teórico, para utilizar a terminologia de Sánchez Gamboa $(1989,2007)$, as pesquisas priorizam análises baseadas em autores vinculados ao método materialista histórico dialético. Entretanto, há um grupo expressivo de pesquisas que trabalham com diálogo entre autores de diferentes perspectivas teóricas, com ênfase na cultura escolar, cotidiano escolar, representação social. Quando se trata das teses, a grande maioria tem aderência ao materialismo histórico dialético. No entanto, as dissertações são as que mais trazem as marcas da pesquisa descritiva, e isso não quer dizer que sejam descomprometidas socialmente. Há um peso do ecletismo teórico nas dissertações e, às vezes, do estabelecimento de uma relação linear entre a concepção da educação rural e a da Educação do Campo, especialmente entre os pesquisadores que se aproximam do tema sem o vínculo com os movimentos sociais.

A análise dos trabalhos permite afirmar que a grande maioria tem aproximação com a perspectiva crítico-dialética, conforme denominada por Sánchez Gamboa (1989, p. 97), ou seja, pesquisas que "(...) questionam fundamentalmente a visão estática da realidade (...) as propostas nelas contidas se caracterizam por destacar o dinamismo da práxis transformadora dos homens como agentes históricos".

Do ponto de vista teórico, as pesquisas que analisam o MST tendem a ter maior vínculo com a teoria social e, portanto, são referenciadas no materialismo histórico dialético. Obras reiteradamente referenciadas são de autores tais como: Gramsci, Hobsbawm, Lênin, Marx, Pistrak, Mészáros e Thompson. Dentre os autores brasileiros envolvidos com o MST, são recorrentes as referências a Ariovaldo Umbelino de Oliveira, Bernardo Mançano Fernandes, João Pedro Stédile e Roseli Salete Caldart. Quando se trata da Educação do Campo, as referências brasileiras presentes em 90\% dos trabalhos são: Caldart, Fernandes, Miguel Arroyo e Mônica Molina. As pesquisas trazem artigos, teses e coletâneas produzidas após a emergência da Educação do Campo (1998), como referenciais importantes, a exemplo de dossiês temáticos de diversos periódicos, coletâneas como as organizadas por Antonio Munarim, Célia Vendramini, Conceição Paludo, Maria Isabel Antunes-Rocha, Mônica Molina, Roseli Caldart, Salomão Hage, entre outros. Nos últimos oito anos, têm sido reiteradas as referências às obras 
de Gaudêncio Frigotto e Luiz Carlos de Freitas, haja vista que o primeiro tem se dedicado às reflexões sobre a escola pública e as políticas educacionais, e o segundo, sobre o empresariamento da educação.

$\mathrm{Na}$ análise do conteúdo de $10 \%$ das pesquisas, trabalhamos com as que deram ênfase à prática educativa, formação de professores (Pedagogia da Terra e Licenciatura em Educação do Campo), trabalho e educação e proposta educacional do MST.

De maneira breve, é possível afirmar que a prática educativa tem sido analisada na escola, em espaços cooperativos nos assentamentos e nos cursos de Pedagogia da Terra e Licenciatura em Educação do Campo. São trabalhos que enfatizam a relação entre educandas/os e educadoras/es, a organização curricular, as condições de trabalho do professor, os processos e dificuldades para realização de formação continuada, relação entre saberes dos povos do campo e os conteúdos escolares, e tecem críticas às pedagogias tradicionais centradas no livro didático e no professor. A maioria das pesquisas identifica a contradição entre o que se propõe na Educação do Campo e o que se vivencia nas escolas públicas.

Os trabalhos que tratam da formação de professores estabelecem relações com as políticas de formação inicial e continuada e tendem a enfatizar a necessidade de que a formação contemple diferentes organizações curriculares e trabalhem com a realidade campo e escolas públicas, incluindo as multisseriadas. Há ênfase nos trabalhos sobre Licenciatura em Educação do Campo (LEDOC) e Pedagogia da Terra como possibilidades de formação crítica e comprometida com um projeto popular para o País. A respeito da produção sobre LEDOC, o texto de Molina, Antunes-Rocha e Martins (2019), que traz o estágio da produção do conhecimento na área, está ao encontro do que identificamos na nossa investigação.

Trabalho e Educação possui um conjunto investigativo que tende a ser fiel ao método materialista histórico dialético, com referências a Marx em especial. Tende a analisar o trabalho como princípio educativo no movimento social, na escola e em contextos de cooperação no MST. Célia Vendramini e Marlene Ribeiro são referências importantes na temática, com várias teses e dissertações orientadas.

Sobre a proposta educacional do MST, o trabalho pioneiro é o de Célia Vendramini (1992), que enfatiza a organização educacional do MST, suas lutas e experiências nas escolas dos assentamentos. Trabalhos mais recentes enfatizam a Escola Itinerante, sua organização pedagógica, as experiências com os complexos de estudo e a preocupação com a formação humana. Duas teses são referências na área, a de Sapelli (2013) e a de Camini (2009). São trabalhos que indicam processos constituídos na e a partir da produção do conhecimento e da crítica à escola pública centrada na lógica estatal.

Em síntese, o fundamental a destacar da produção do conhecimento sobre MST e Educação do Campo é que ela enfoca a prática social em movimento e em contradição. Após 20 anos de Educação do Campo, constata-se que são muitas as pesquisas voltadas para o tema em articulação com a formação de professores, políticas educacionais, escolas públicas, organização curricular, práticas pedagógicas, emancipação humana, Educação Básica, Trabalho e Educação, entre outros. São pesquisas que dão visibilidade às experiências construídas com os sujeitos do campo e no processo de luta pela reforma agrária e por projeto popular de sociedade.

\section{TENDÊNCIAS E LACUNAS}

As pesquisas produzidas no contexto das experiências do MST e da Educação do Campo problematizam a relação entre sociedade e governos, o vínculo entre trabalho e educação e aspectos vinculados ao mundo escolar. Sobre a escola, algumas indagações e lutas chamam a atenção nas pesquisas, a saber: 1) participação dos professores em processos de formação continuada; 2) propostas de diminuição da rotatividade de professores, possibilitando a formação e a inserção de pessoas do lugar no trabalho pedagógico nas escolas; 3) reivindicações dos movimentos sociais quanto à permanência das escolas no campo e demandas quanto aos conteúdos escolares - reivindica-se que os conteúdos escolares valorizem a cultura dos povos do campo e que façam ampliar os conhecimentos já adquiridos pela população em sua experiência de vida; 4) discussão, em praticamente todo o território nacional, sobre a Educação do Campo, mediante a realização de seminários estaduais e conferências nacionais, que colocam, na ordem do dia, políticas públicas de educação aos povos do campo, segundo as suas 
necessidades; 5) diversificação das experiências educativas no campo, a exemplo das Casas Familiares Rurais, Escolas Família Agrícola, Escolas Itinerantes etc.; 6) experiências de parcerias entre universidades, movimentos sociais e governos, na realização de Educação Superior voltada aos povos do campo, particularmente aos assentados da reforma agrária, como resultado da ação dos movimentos sociais e, mais precisamente, do MST; 7) fortalecimento do debate sobre educação e movimentos sociais do campo - criação de grupos de estudos e pesquisas sobre o tema e, com isso, a ampliação do número de teses e dissertações que se dedicam à compreensão e contribuição na construção de uma política pública de educação dos povos do campo; 8) fortalecimento da concepção de Educação em Alternância - com a organização do trabalho pedagógico muito próximo ao que discute Pistrak em sua obra Fundamentos da escola do trabalho.

A primeira década do século XXI vem demonstrando que os movimentos sociais (por meio dos seus assessores, lideranças, educadores e educandos) adentraram o espaço universitário e com isso potencializaram os grupos de estudos e de pesquisas e as experiências no âmbito da Educação Superior e Pós-Graduação. Pode-se dizer que os movimentos sociais levaram referenciais teóricos à universidade, também. Com isso, a própria universidade vem se modificando para o novo que surge na Educação Superior - as demandas dos movimentos sociais do campo por cursos de graduação e de pós-graduação. Os concursos públicos nas universidades federais para a área da Educação do Campo vêm surgindo em função dos cursos de Pedagogia da Terra, Licenciatura em Educação do Campo e Especialização em Educação do Campo. Dessas experiências são elaboradas teses, dissertações e livros que expressam a produção coletiva no contexto do movimento nacional da Educação do Campo e problematizam as contradições da sociedade brasileira. São organizados os encontros nacionais e internacionais, dos quais resultam produções coletivas, a exemplo das organizadas por Molina (2006), Munarim et al (2010), Paludo (2014) e Wizniewsky (2016), entre tantas outras.

Uma tendência a ser considerada na pesquisa educacional sobre o MST e a Educação do Campo refere-se às intervenções nas práticas educativas na escola, algo que vem ocorrendo no contexto das escolas itinerantes, como demonstrado por Sapelli (2013), Camini (2009) e Mariano (2016). Essas três pesquisas, além das críticas que tecem à educação brasileira, empenham-se em mostrar a construção da experiência coletiva, as mudanças possíveis a partir do aprofundamento do conhecimento educacional sobre currículo e organização do trabalho pedagógico.

Há lacunas importantes a serem vencidas na pesquisa educacional, a exemplo do tema "interface” entre Educação Especial e Educação do Campo e, também, da relação entre Educação Ambiental e Educação do Campo. Sobre esses temas e a preocupação de se compreenderem interfaces, consideramos algumas pesquisas como exemplares do avanço no debate. Destacamos os trabalhos de Nozu (2017), Khun (2017), Silva (2017) e Anjos (2016), respectivamente, tese e dissertações que trazem a preocupação explícita com a "interface" entre Educação Especial e Educação do Campo. E, também, a tese de Buczenko (2017), que analisou interface entre Educação Ambiental e Educação do Campo a partir de estudo sobre práticas pedagógicas em escolas públicas localizadas no campo em áreas de proteção ambiental.

Outras lacunas têm relação com o envelhecimento no contexto da agricultura familiar e dos assentamentos da reforma agrária, bem como dos processos formativos e políticas públicas voltadas para a Agroecologia. Há número reduzido de pesquisas sobre as duas temáticas na área educacional, da mesma forma que os problemas relacionados à tecnologia educacional no campo e nas escolas carecem de mais investigação, incluindo as disputas político-pedagógicas em torno do tema, a exemplo da que se instala a partir do projeto denominado "Escolas Rurais Conectadas", mantido por empresa do ramo das telecomunicações.

Conhecer as pesquisas e as lacunas ainda presentes na investigação educacional voltada à compreensão da educação e dos movimentos sociais do campo é fundamental para fazer avançar o conhecimento e evitar repetições desnecessárias sobre conceitos e contextos já investigados. Existem teses e dissertações que pouco ou nada mencionam de referências existentes sobre o tema investigado, demonstrando fragilidade na produção/continuidade da produção do conhecimento. Quando mencionamos "referências", pensamos nas teses e dissertações que já se dedicaram aos temas movimentos sociais e Educação do Campo. As pesquisas mencionam as referências clássicas, nacionais 
e internacionais, mas, muitas vezes, esquecem-se de mencionar o estágio atual do conhecimento na área investigada no próprio país. Repete-se a origem do MST em boa parte das pesquisas, assim como se repete a origem da Educação do Campo na grande maioria das teses e dissertações que optam por investigar o tema, como se pouco ou nada existisse de pesquisa já realizada na pós-graduação na área. Os núcleos e grupos de pesquisas têm potenciais para mudar essa realidade, socializando o máximo de pesquisas existentes no País e orientando os novos pesquisadores a realizar vasto levantamento bibliográfico nos bancos digitais de teses e dissertações, quando iniciam os estudos na pós-graduação.

\section{CONSIDERAÇÕES FINAIS}

Constatamos que o cenário da produção de pesquisas educacionais que têm como objeto o MST e a Educação do Campo tem sido profícuo no que tange à problematização das contradições que marcam o campo no Brasil há séculos e no que diz respeito à escolarização dos povos do campo, que adquire novos contornos com o Movimento Nacional da Educação do Campo. Afinal, os coletivos do campo colocam em questão o projeto político de campo no Brasil e o projeto educacional dos povos do campo. São séculos de exclusão e de desigualdade educacional entre os povos do campo, permeados por conjunturas e projetos educacionais que fortaleciam o ideário do urbano como lugar de desenvolvimento e que ressaltavam o rural como lugar do atraso. Verificamos a presença de pesquisas em contextos regionais que pouco problematizavam a educação dos e com os povos do campo. São pesquisas que desejam interferir na realidade, seja ela escola, gestão educacional e políticas locais.

As pesquisas analisam políticas educacionais, práticas educativas, organização do trabalho pedagógico, formação de professores, entre outros temas. O que diferencia as pesquisas atuais daquelas feitas na segunda metade do século XX é o caráter de investigação-ação, mediante trabalho coletivo, e a natureza de pesquisas participantes, haja vista que diversos autores são sujeitos com vínculos orgânicos com a classe trabalhadora do campo. Novas linhas de pesquisa surgem nos programas de pós-graduação, motivadas pela dinâmica societária de lutas, conquistas e proposições de políticas e práticas educacionais.

A produção do conhecimento referenciado na prática social gera impactos na universidade, nas instituições de educação básica, na formação escolar e humana dos trabalhadores e povos do campo. Há um efeito espiral ascendente em direção à transformação social, mediante o aprofundamento vertical do conhecimento da experiência e da ciência. A luta por políticas públicas que possam fortalecer os processos formativos e a construção coletiva de conhecimentos tem sido uma constante nos movimentos sociais. Não menos importante, as lutas atuais pelos investimentos em pesquisas na área das Ciências Humanas continuam. Fundamental analisar e fortalecer impactos nas escolas públicas e nas políticas locais, em que pese a conjuntura (2019-2022) mostrar sinais de que não haverá diálogo governamental com a sociedade civil, voltado para construção de políticas públicas. É possível que nessa conjuntura as dissertações e teses possam trazem o panorama de recuo em curso. Ou, ainda, pode ser que analisem os coletivos de resistência vivos na sociedade brasileira, embora nem sempre com visibilidade no cenário político.

\section{REFERÊNCIAS}

ALBUQUERQUE, Joelma de Oliveira. Crítica à produção do conhecimento sobre a Educação do Campo no Brasil: teses e antíteses sobre a educação dos trabalhadores no início do século XXI. 247 f. Tese (Doutorado em Educação), Universidade Estadual de Campinas, Faculdade de Educação, Campinas, SP. 2011.

ANJOS, Christiano Felix dos. Realidades em contato: construindo uma interface entre educação especial e a Educação do Campo. 228 fls. Dissertação (Mestrado em Educação), Universidade Federal do Espírito Santo, Vitória, 2016. 
BRASIL. Lei $\mathbf{n}^{\circ} \mathbf{1 2 . 9 6 0}$ de março de 2014. Altera a Lei no ${ }^{\circ} .394$, de 20 de dezembro de 1996, que estabelece as diretrizes e bases da educação nacional, para fazer constar a exigência de manifestação de órgão normativo do sistema de ensino para o fechamento de escolas do campo, indígenas e quilombolas. Publicado no DOU em 28 de março de 2014. Brasília, 2014.

BUCZENKO, Gerson Luiz. Educação Ambiental e Educação do Campo: o trabalho do Coordenador Pedagógico em escola pública localizada em Área de Proteção Ambiental. 2017. 344 f. Tese (Doutorado em Educação), Universidade Tuiuti do Paraná, Curitiba, 2017.

CAMINI, Isabela. Escola itinerante do MST: um contraponto à escola capitalista? $254 \mathrm{f}$. Tese (Doutorado em Educação), Programa de Pós-Graduação da Faculdade de Educação, Universidade Federal do Rio Grande do Sul, 2009.

FÓRUM NACIONAL DE EDUCAÇÃO DO CAMPO - FONEC. III Seminário Nacional. Documento Final. Brasília, 26 a 28 de agosto de 2015.

GHEDINI, Cecília Maria. Produção da Educação do Campo no Brasil: das referências históricas à institucionalização. 356 f. Tese (Doutorado em Educação), Programa de Pós-Graduação em Educação, Universidade Estadual do Rio de Janeiro, 2015.

KHUN, Ernane Ribeiro. A Educação Especial na Educação do Campo: as configurações da rede municipal de ensino. 82 f. Dissertação (Mestrado em Educação), Universidade Federal de Santa Maria, 2017.

MAINARDES, Jefferson. Metapesquisa no campo da política educacional: elementos conceituais e metodológicos. Educar em Revista, Curitiba, v. 34, n. 72, p. 303-319, nov./dez. 2018.

MINISTÉRIO DA EDUCAÇÃO. CAPES. Portaria $\mathbf{n}^{\mathbf{0}} 13$ de fevereiro de 2006, institui a divulgação digital das teses e dissertações produzidas pelos programas de doutorado e mestrado reconhecidos. Brasília, 2006.

MINISTÉRIO DA EDUCAÇÃO. CAPES. Documento de Área. Área 38: Educação. Brasília, 2019.

MOLINA, Mônica Castagna (Org.). Educação do Campo e pesquisa: questões para reflexão. Brasília: Ministério do Desenvolvimento Agrário, 2006.

MOLINA, Mônica Castagna; ANTUNES-ROCHA, Maria Isabel; MARTINS, Maria de Fátima Almeida. A produção do conhecimento na licenciatura em Educação do Campo: desafios e possibilidades para o fortalecimento da educação do campo. Revista Brasileira de Educação, v. 24 e240051, 2019.

MUNARIM, Antonio et al. (Org.). Educação do Campo: reflexões e perspectivas. Florianópolis: Insular, 2010.

MUNARIM, Antonio. Movimento Nacional de Educação do Campo: uma trajetória em construção. Trabalho apresentado na 31. Reunião Anual da ANPEd, Caxambu, 2008. Disponível em: <http://www.anped.org.br>. (GT 3 - Movimentos Sociais e Educação). Acesso em: 2 out. 2019.

NOZU, Washington César Shoiti. Educação Especial e Educação do Campo: entre porteiras marginais e fronteiras culturais. 235 f. Tese (Doutorado em Educação), Universidade Federal da Grande Dourados, Dourados, 2017.

OLIVEIRA, Marcos Antonio de. As bases filosóficas e epistemológicas de alguns Projetos de Educação do Campo: do pretendido Marxismo à aproximação ao Ecletismo Pós- Moderno. 481 fls. Tese 
(Doutorado em Educação), Programa de Pós-Graduação em Educação, Universidade Federal do Paraná, 2008.

PALUDO, Conceição. (org.). Campo e cidade: em busca de caminhos comuns. Pelotas: Editora da UFPel, 2014.

PEREIRA, Camila Casteliano. A política de fechamento de escolas localizadas no campo na Região Metropolitana de Curitiba. 192 f. Dissertação (Mestrado em Educação) - Universidade Tuiuti do Paraná, Curitiba 2017.

PNERA - Pesquisa Nacional sobre a Educação na Reforma Agrária II. Brasília, junho de 2015. Disponível em: http://www.ipea.gov.br/portal/index.php?option=com_ content\&view $=$ article\&id $=25640$. Acesso em: 25 set. 2015.

SÁNCHEZ GAMBOA, Silvio Áncizar. Pesquisa em educação: métodos e epistemologias. Chapecó: Argos, 2007.

SAPELLI, Marlene. Escola do campo - espaço de disputa e de contradição: análise da proposta pedagógica das escolas itinerantes do Paraná e do Colégio Imperatriz Dona Leopoldina. $448 \mathrm{f}$. Tese (Doutorado em Educação), Centro de Ciências da Educação, Programa de Pós-Graduação em Educação, Universidade Federal de Santa Catarina, 2013.

SANCHEZ Gamboa, Sílvio Áncizar. A dialética na pesquisa em educação: elementos de contexto. In: FAZENDA, Ivani (Org.). Metodologia da Pesquisa em Educação. São Paulo: Cortez, 1989.

SILVA, Régis Henrique dos Reis Silva; SÁNCHEZ GAMBOA, Sílvio Áncizar. Do esquema paradigmático à matriz epistemológica: sistematizando novos níveis de análise. ETD - Educação Temática Digital, v. 16. n. 1, 2014: Pesquisa, desenvolvimento e formação na educação. Campinas. Disponível em https://periodicos.sbu.unicamp.br/ojs/index.php/etd/article/view/1329. Acesso em: 20 set. nov. 2019.

SILVA, Leandro Ferreira da. Políticas públicas de educação inclusiva: interfaces da educação especial na Educação do Campo no município de Conceição do Araguaia-PA. Dissertação (Mestrado em Educação Agrícola), Universidade Federal Rural do Rio de Janeiro, 2017.

SOUSA, Sandra Zákia; BIANCHETTI, Lucídio. Pós-graduação e pesquisa em educação no Brasil: o protagonismo da ANPEd. Revista Brasileira de Educação, v. 12, n. 36, set./dez. de 2007. P. 389-546.

SOUZA, Maria Antônia de. A pesquisa sobre educação e o Movimento dos Trabalhadores Rurais Sem Terra (MST) nos programas de pós-graduação em Educação. Revista Brasileira de Educação, v. 12, n. 36, set./dez. 2007. P. 443-548.

SOUZA, Maria Antônia de. Educação e movimentos sociais do campo: a produção do conhecimento no período de 1987 a 2015. 2. ed., atualizada e revisada. Curitiba: UFPR, 2016 a.

SOUZA, Maria Antônia de. A Educação do Campo no Brasil. In: SOUZA, Elizeu Clementino de; CHAVES, Vera Lúcia Jacob. (Orgs.). Documentação, memória e história da educação no Brasil: diálogos sobre políticas de educação e diversidade. Vol. 1. Tubarão: Copiart, 2016b. P. 133-157.

SOUZA, Marilsa Miranda de. Imperialismo e Educação do Campo: uma análise das políticas educacionais no Estado de Rondônia a partir de 1990. 405 f. Tese (Doutorado em Educação Escolar), Universidade Estadual Paulista, Faculdade de Ciências e Letras, Campus de Araraquara, 2010. 
VENDRAMINI, Célia Regina. Ocupar, resistir e produzir: um estudo da proposta pedagógica do MST. Dissertação (Mestrado em Educação), Universidade Federal de São Carlos, 1992.

WERLE, Flávia Obino Corrêa (Org.). Educação rural em perspectiva internacional: instituições, práticas e formação do professor. Ijuí: Editora da Unijuí, 2007.

WIZNIEWSKY, Carmen Rejane Flores; MOURAD, Leonice Aparecida de Fátima Alves (Orgs.). Educação, memória e resistência popular na formação social da América Latina. Porto Alegre: Evangraf, 2016.

Submetido: $21 / 07 / 2018$

Aprovado: $22 / 01 / 2020$

Contato:

Maria Antônia de Souza Rua Dona Alice Tibiriçá, no 652. Curitiba|PR |Brasil CEP 80730-320 